\title{
Effects of Low-dose Infliximab on Spinal Inflammation on Magnetic Resonance Imaging in Ankylosing Spondylitis
}

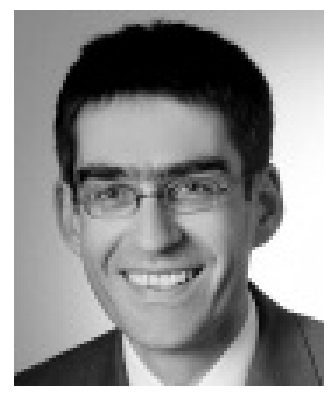

In 2003, infliximab was the first anti-tumor necrosis factor (TNF) agent to be approved by both the European Medicines Agency and the US Food and Drug Administration for the treatment of active ankylosing spondylitis (AS) that responds insufficiently to standard therapy, usually nonsteroidal antiinflammatory drugs. All initial trials in AS - whether the initial open-label studies or placebo-controlled trials - were conducted using the 5 $\mathrm{mg} / \mathrm{kg}$ infliximab dosing scheme $\mathrm{e}^{1,2}$. In the placebo-controlled trial of 69 patients from Germany that led to approval of the drug, the interval between infliximab $5 \mathrm{mg} / \mathrm{kg}$ infusions was 6 weeks after the initial infusions at Week 0, Week 2 , and Week $6^{1}$. The dose and infusion interval of infliximab in AS clinical trials was chosen in analogy to the treatment schedule of infliximab in Crohn's disease because according to the concept of spondyloarthritis as a group of interrelated diseases, Crohn's disease appeared to be more akin to AS than rheumatoid arthritis (RA) and was the first spondyloarthropathy related disease for which approval of infliximab had been obtained. Therefore, the $5 \mathrm{mg} / \mathrm{kg}$ infliximab dose given every 6 or 8 weeks was used in the clinical trials in $\mathrm{AS}$, and not the $3 \mathrm{mg} / \mathrm{kg}$ dose every 8 weeks that had been approved in RA. Unfortunately and in contrast to RA, no dose-finding studies with infliximab were ever performed in AS. Thus, from a scientific point of view we simply do not know whether infliximab $5 \mathrm{mg} / \mathrm{kg}$ every 6 weeks is the optimum treatment schedule for active AS.

In recent years a few clinical studies were published using the $3 \mathrm{mg} / \mathrm{kg}$ dose of infliximab in AS given every 8 weeks. In summary, these usually small and open-label studies revealed response rates that were similar to ${ }^{3,4}$ or lower than ${ }^{5}$ those reported from studies using the approved dosing scheme of $5 \mathrm{mg} / \mathrm{kg}$ every 6 weeks. In the context of lack of properly controlled dose-finding studies, the CANDLE trial is of interest since it was the first controlled trial, with 76 patients, assessing the efficacy of 3 infusions of infliximab $3 \mathrm{mg} / \mathrm{kg}$ given at Weeks 0,2 , and 6 in active AS versus placebo over a 12 week period, followed by an open extension phase until Week 50 . The primary outcome of the CANDLE trial was the proportion of patients achieving an Assessments of SpondyloArthritis International Society (ASAS) improvement of at least 20\% (ASAS20) at Week 12. ASAS20 was achieved by $53.8 \%$ of infliximab-treated patients versus $30.6 \%$ of placebo-treated patients $(\mathrm{p}=$ 0.042 ), and an ASAS40 response was achieved by $46 \%$ and $8 \%$ of infliximab and placebo treated patients, respectively $(\mathrm{p}<0.01)$. However, a major clinical response defined by Bath Ankylosing Spondylitis Disease Activity Index (BASDAI) improvement of at least 50\% (BASDAI50) was achieved by a smaller proportion of patients in CANDLE as compared to published controlled trials using the $5 \mathrm{mg} / \mathrm{kg}$ dose: Only $28 \%$ of infliximab-treated versus $11 \%$ of placebo-treated patients achieved BASDAI50 at Week 12 . Therefore, $62 \%$ of patients treated with infliximab $3 \mathrm{mg} / \mathrm{kg}$ who did not reach BASDAI50 at Week 22 or Week 38 had a dose increase of infliximab to $5 \mathrm{mg} / \mathrm{kg}$ during the openlabel extension period. This dose increase seemed to have benefited patients, since at Week 50 around $66 \%$ of patients treated with infliximab during the blinded phase (first 12 weeks) of the trial achieved BASDAI50 $0^{6}$. However, the ASAS40 response rate also increased from $46 \%$ at Week 12 to $67 \%$ at Week 50 of the open-label phase, rendering inferences about the efficacy of the dose increase difficult. Thus, from this trial we can state that the $3 \mathrm{mg} / \mathrm{kg}$ dose of infliximab is clinically effective, but we can only carefully infer that low-dose infliximab may be less effective than the 5 $\mathrm{mg} / \mathrm{kg}$ dose. Unfortunately, the CANDLE trial did not directly compare infliximab at a dose of $3 \mathrm{mg} / \mathrm{kg}$ with infliximab at a dose of $5 \mathrm{mg} / \mathrm{kg}$ during the blinded phase of the study, which would have been more informative.

In the CANDLE trial the effect of low-dose infliximab $(3 \mathrm{mg} / \mathrm{kg}$ ) on spinal inflammation detectable by magnetic resonance imaging (MRI) was assessed in detail and is reported by Maksymowych, et al in this issue of The

See Trial of low dose infliximab in AS, June 2010 and

Low-dose infliximab reduces spinal inflammation in active AS, page 1728

Personal non-commercial use only. The Journal of Rheumatology Copyright @ 2010 . All rights reserved. 
Journal $^{7}$. MRI of the spine was performed at baseline and after 12 weeks in 2 out of 8 centers of the CANDLE trial. Complete MRI data were available for 32 patients (16 patients treated with infliximab and 16 patients treated with placebo). Using the Spondyloarthritis Research Consortium of Canada (SPARCC) MRI index, which focuses on the 6 most affected discovertebral units (DVU), a mean reduction of active spinal inflammation by $55 \%$ was found in infliximab-treated patients after 12 weeks, whereas an increase of $6 \%$ was found in the placebo-treated AS patients, resulting in a very good Guyatt's effect size of at least 1.7 . In this MRI substudy an ASAS20 response was achieved by $68.8 \%$ of infliximab-treated versus $37.5 \%$ of placebo-treated patients $(\mathrm{p}=0.08)$, ASAS40 by $56.3 \%$ versus $12.5 \%(\mathrm{p}=$ 0.009 ), and BASDAI 50 by $31.3 \%$ versus $6.3 \%$ ( $\mathrm{p}=$ nonsignificant), respectively.

Notably, the reduction of active spinal inflammation was independent of clinical response, i.e., independent of achievement of ASAS20 response. The uncoupling of the clinical response and reduction of MRI spinal inflammatory activity was also reported in an earlier study in 82 patients with active AS who were treated with the standard dose of adalimumab of $40 \mathrm{mg}$ every other week ${ }^{8}$. Also applying the SPARCC system, the authors found a similar reduction of spinal inflammation of 54\% after 12 weeks of adalimumab and an increase of $9 \%$ in the placebo group. Mean baseline MRI scores were similar in the adalimumab study (mean score 16.0 in the adalimumab group, 19.9 in the placebo group) and the CANDLE trial (mean score 16.4 infliximab group, 17.7 placebo group). Although direct comparison of 2 independent studies is scientifically never sound, one still gets the impression that a similar degree of reduction of MRI spinal inflammation was seen after 12 weeks with either adalimumab in standard dose or with infliximab in the $3 \mathrm{mg} / \mathrm{kg}$ dose.

In other anti-TNF studies in AS, different MRI scoring systems [usually the ASspiMRI-a (AS spinal MRI activity), score $^{9}$ or modification thereof ${ }^{10,11}$ ] and different followup periods of between 6 and 24 weeks were applied to assess the course of spinal inflammation during therapy. The shortest followup study assessed MRI after 6 weeks of etanercept in the standard dose of $25 \mathrm{mg}$ given subcutaneously twice weekly ${ }^{10}$ : MRI spinal inflammatory activity was found to be reduced by $39.7 \%$ after only 6 weeks of etanercept ${ }^{10}$. Another study on etanercept assessed MRI changes after 12 weeks and found a reduction in MRI spinal inflammatory activity of $54 \%{ }^{12}$. A study using infliximab $5 \mathrm{mg} / \mathrm{kg}$ also assessed MRI changes after 12 weeks and reported a reduction of MRI spinal inflammatory activity of $48 \%{ }^{9}$. In the large ASSERT trial in 194 patients with active AS treated with infliximab $5 \mathrm{mg} / \mathrm{kg}$, MRI was performed after 24 weeks of therapy, with a reduction in MRI spinal inflammation of $75 \%$ (Guyatt's effect size 1.5$)^{13}$. The above mentioned etanercept study had another MRI assessment, also after 24 weeks, and found a reduction in inflammation of $69 \%{ }^{10}$. Comparing and weighing the results from these various studies using different anti-TNF agents, different scoring systems, and various followup periods is difficult. Despite these limitations, with the 3 anti-TNF agents infliximab, etanercept, and adalimumab, reductions in active spinal inflammation detectable by MRI of around 40\%-70\% can be observed after 6 to 24 weeks of therapy, with a tendency for a greater reduction in spinal inflammation with longer duration of therapy. Further, it seems that infliximab at a dose of $3 \mathrm{mg} / \mathrm{kg}$ as used in the CANDLE trial is very effective in reducing active spinal inflammation on MRI after 12 weeks of therapy and may be as effective as 5 $\mathrm{mg} / \mathrm{kg}^{7}$. However, we do not know the longterm effect of low-dose infliximab on spinal inflammation and a direct comparison of the low dose of infliximab of $3 \mathrm{mg} / \mathrm{kg}$ with the standard dose of $5 \mathrm{mg} / \mathrm{kg}$ on MRI spinal inflammation in AS was unfortunately not undertaken in the CANDLE trial. Given all the limitations outlined above, low-dose infliximab may suffice for the treatment of a proportion of patients and may help reduce treatment costs in AS.

The general question arises whether anti-TNF treatment for longer than 24 weeks further decreases active spinal inflammation on MRI. In this regard it is notable that in the adalimumab study ${ }^{8}$ no further reduction of inflammation after one year of treatment in comparison to 12 weeks was found using the SPARCC system (mean score 16.0 at baseline, 6.7 after 12 weeks and 6.2 after 52 weeks). Whether this lack of further decrease in inflammation beyond week 12 is related to the anti-TNF agent adalimumab or to any other factor cannot be deduced from the available data. Similarly, in a 2 -year followup study ${ }^{14}$ of the etanercept study ${ }^{10}$, the $78 \%$ reduction (vs baseline) was not much greater than the $75 \%$ reduction observed after 24 weeks. However, the number of patients available after 2 years in this study was very small $(n=7)$. In contrast, in a 2-year followup study of infliximab $5 \mathrm{mg} / \mathrm{kg}$ (standard dose), a decrease of MRI spinal inflammatory activity of $69 \%$ was found at Year 2 versus $48 \%$ after 12 weeks ${ }^{15}$. Thus, after 24 weeks of therapy a steady state seems to occur, with no further relevant changes in mean MRI scores, i.e., at the group level. Of importance, none of the longer followup studies reported a complete suppression of spinal inflammation in all patients: a minimal amount of active inflammation on MRI was detectable after 2 years in the etanercept study in $64 \%$ of patients ${ }^{14}$, and in the infliximab $5 \mathrm{mg} / \mathrm{kg}$ study in $79 \%$ of patients ${ }^{15}$. Taken together, anti-TNF therapy in AS substantially reduces spinal inflammation detectable by MRI, but continuous anti-TNF therapy appears to fail to completely abolish active inflammation on MRI. Whether the latter is related to incomplete suppression of active inflammatory sites that are already present at baseline, or whether this is due to new sites of active inflammation that arise during therapy cannot be derived from the available data. 
The relation between MRI spinal inflammation and formation of syndesmophytes in AS remains to be elucidated. Followup studies suggest that new syndesmophytes preferentially arise after 2 years at sites with previous active inflammation on MRI, particularly if the inflammation is no longer present after 2 years of anti-TNF therapy 16,17 . However, longer followup periods with frequent MRI assessments that investigate the longterm fate of a site of active inflammation are not available. Potentially, complete suppression of inflammation - if ever achievable - may interrupt the formation of new syndesmophytes after a yet to be defined period of time of repair ${ }^{18}$. Future research will hopefully teach us whether this low degree of spinal inflammation despite continuous anti-TNF therapy is the main stimulus for sustained formation of syndesmophytes in AS.

MARTIN RUDWALEIT, $\mathrm{MD}$,

Charité University Medicine,

Campus Benjamin Franklin,

Department of Medicine,

Berlin, Germany

Address correspondence to Dr. M. Rudwaleit, Department of Rheumatology, Ev. Krankenhaus Hagen-Haspe, Brusebrinkstrasse 20, 58135 Hagen, Germany.E-mail: rudwaleit@evk-haspe.de The author has received speaking fees and/or honoraria for advisory board meetings from Abbott, Centocor, Schering-Plough, MSD, Pfizer, Roche, and Wyeth.

\section{REFERENCES}

1. Braun J, Brandt J, Listing J, Gromnica-Ihle E, Kellner H, Krause A, et al. Treatment of active ankylosing spondylitis with infliximab - a double-blind placebo controlled multicenter trial. Lancet 2002;359:1187-93.

2. Van Den Bosch F, Kruithof E, Baeten D, Herssens A, de Keyser F, Mielants H, et al. Randomized double-blind comparison of chimeric monoclonal antibody to tumor necrosis factor alpha (infliximab) versus placebo in active spondylarthropathy. Arthritis Rheum 2002;46:755-65.

3. Maksymowych WP, Jhangri GS, Lambert RG, Mallon C, Buenviaje $\mathrm{H}$, Pedrycz E, et al. Infliximab in ankylosing spondylitis: a prospective observational inception cohort analysis of efficacy and safety. J Rheumatol 2002;29:959-65.

4. Jois RN, Leeder J, Gibb A, Gaffney K, Macgregor A, Somerville M, et al. Low-dose IFX treatment for ankylosing spondylitis clinically- and cost-effective. Rheumatology 2006;45:1566-9.

5. Sidiropoulos P, Kritikos HD, Siakka P, Mamoulaki M, Kouroumali $\mathrm{H}$, Voudouris $\mathrm{K}$, et al. Low dose of infliximab is inadequate in most patients with spondylarthropathies. Clin Exp Rheumatol 2005;23:513-6.

6. Inman RD, Maksymowych WP. A double-blind, placebo-controlled trial of low-dose infliximab in ankylosing spondylitis. J Rheumatol 2010;37:1203-10.
7. Maksymowych WP, Salonen D, Inman R, Rahman P, Lambert RGW. Low-dose infliximab (3 mg/kg) significantly reduces spinal inflammation on MRI in patients with active ankylosing spondylitis: a randomized placebo-controlled study. J Rheumatol 2010;37:1728-34.

8. Lambert RG, Salonen D, Rahman P, Inman RD, Wong RL, Einstein $\mathrm{SG}$, et al. Adalimumab significantly reduces both spinal and sacroiliac joint inflammation in patients with ankylosing spondylitis: a multicenter, randomized, double-blind, placebo-controlled study. Arthritis Rheum 2007;56:4005-14.

9. Braun J, Baraliakos X, Golder W, Brandt J, Rudwaleit M, Listing J, et al. Magnetic resonance imaging examinations of the spine in patients with ankylosing spondylitis, before and after successful therapy with infliximab: evaluation of a new scoring system. Arthritis Rheum 2003;48:1126-36.

10. Rudwaleit M, Baraliakos X, Listing J, Brandt J, Sieper J, Braun J. Magnetic resonance imaging of the spine and the sacroiliac joints in ankylosing spondylitis and undifferentiated spondyloarthritis during treatment with etanercept. Ann Rheum Dis 2005;64:1305-10.

11. Rudwaleit M, Schwarzlose S, Hilgert ES, Listing J, Braun J, Sieper J. MRI in predicting a major clinical response to anti-tumour necrosis factor treatment in ankylosing spondylitis. Ann Rheum Dis 2008;67:1276-81.

12. Baraliakos X, Davis J, Tsuji W, Braun J. Magnetic resonance imaging examinations of the spine in patients with ankylosing spondylitis before and after therapy with the tumor necrosis factor alpha receptor fusion protein etanercept. Arthritis Rheum 2005;52:1216-23.

13. Braun J, Landewé R, Hermann KG, Han J, Yan S, Williamson P, van der Heijde D; ASSERT Study Group. Major reduction in spinal inflammation in patients with ankylosing spondylitis after treatment with infliximab: results of a multicenter, randomized, double-blind, placebo-controlled magnetic resonance imaging study. Arthritis Rheum 2006;54:1646-52.

14. Baraliakos X, Brandt J, Listing J, Haibel H, Sörensen H, Rudwaleit $\mathrm{M}$, et al. Outcome of patients with active ankylosing spondylitis after two years of therapy with etanercept: clinical and magnetic resonance imaging data. Arthritis Rheum 2005;53:856-63.

15. Sieper J, Baraliakos X, Listing J, Brandt J, Haibel H, Rudwaleit M, et al. Persistent reduction of spinal inflammation as assessed by magnetic resonance imaging in patients with ankylosing spondylitis after 2 yrs of treatment with the anti-tumour necrosis factor agent infliximab. Rheumatology 2005;44:1525-30.

16. Baraliakos X, Listing J, Rudwaleit M, Sieper J, Braun J. The relationship between inflammation and new bone formation in patients with ankylosing spondylitis. Arthritis Res Ther 2008;10:R104

17. Maksymowych WP, Chiowchanwisawakit P, Clare T, Pedersen SJ, Østergaard M, Lambert RG. Inflammatory lesions of the spine on magnetic resonance imaging predict the development of new syndesmophytes in ankylosing spondylitis: evidence of a relationship between inflammation and new bone formation. Arthritis Rheum 2009;60:93-102.

18. Sieper J, Appel H, Braun J, Rudwaleit M. Critical appraisal of assessment of structural damage in ankylosing spondylitis: implications for treatment outcomes. Arthritis Rheum 2008; 58:649-56.

J Rheumatol 2010;37:1553-5; doi:10.3899/jrheum.100422 